\title{
Olanzapine-mediated cardiotoxicity is associated with altered energy metabolism in isolated rat hearts
}

\author{
Patrik Gulac1,2, Maria R. Arnold², Marian Grman³, Thierry P. Carrel2, Sarah L. Longnus², \\ Tatiana Stankovicova ${ }^{1}$ and Lenka Tomasova1,3曰 \\ 'Department of Pharmacology and Toxicology, Faculty of Pharmacy, Comenius University in Bratislava, Bratislava, Slovak Republic; ${ }^{2}$ Department \\ of Cardiovascular Surgery, Inselspital, Bern University Hospital and Department for BioMedical Research, University of Bern, Bern, Switzerland; \\ ${ }^{3}$ Institute of Clinical and Translational Research, Biomedical Research Center, Slovak Academy of Sciences, Bratislava, Slovak Republic
}

\begin{abstract}
Olanzapine is an antipsychotic drug routinely used for the treatment of schizophrenia. Although the olanzapine treatment is associated with disturbed electrical heart activity, the exact mechanism underlying this severe adverse effect remains unclear. Recently, olanzapine administration was demonstrated to be associated with elevation of blood glucose and lower levels of free fatty acids. Therefore, we investigated the effect of acute olanzapine administration on pathways regulating the cardiac energy metabolism in an isolated heart. Electrical activity and contractile parameters were recorded in isolated, spontaneously beating, adult male rat hearts, perfused with either olanzapine $(100 \mathrm{nmol} / \mathrm{l})$ or the vehicle for $10 \mathrm{~min}$. Regulation of key signalling molecules was evaluated by immunoblotting and ATP levels were measured spectrophotometrically. Olanzapine prolonged the QTc intervals and induced a higher number of premature ventricular beats. Furthermore, olanzapine significantly decreased the coronary flow, the rate-pressure product and the contractility $(+d P / d t$ and $-d P / d t)$. These changes were associated with an increased acetyl-CoA carboxylase phosphorylation and tissue ATP levels. We also found a trend for lower phosphorylation levels of Akt and its downstream products AS160, a key regulator of GLUT4 trafficking and glycogen synthase kinase-3ß in olanzapine-treated hearts when compared to vehicletreated controls. These data should contribute to the elucidation of mechanisms that underlie the adverse cardiac effects of olanzapine.
\end{abstract}

Key words: olanzapine, cardiotoxicity, ventricular arrhythmias, ATP, acetyl-CoA carboxylase

Received: 13 September, 2019; revised: 10 December, 2019; accepted: 10 January, 2020; available on-line: 30 January, 2020

凶e-mail: lenka.tomasova@savba.sk

Acknowledgements of Financial Suport: This work was supported by the Slovak Research and Development Agency [grant number VEGA/1/1342/12, FaF UK/47/2016, VEGA/2/0124/19, and VEGA/2/0014/17]. P.G. was supported by the National Scholarship Programme of the Slovak Republic and the University Science Park for Biomedicine [ITMS 26240220087].

Abbreviations: ACC, acetyl-CoA carboxylase; AMPK, 5'AMP-activated protein kinase; CF, coronary flow; CPT-I, carnitine palmitoyltransferase I; ECG, electrocardiogram; FCCP, phenylhydrazone; GSK, glycogen synthase kinase; HR, heart rate; LVP, left ventricular pressure; PDH, pyruvate dehydrogenase; ROS, reactive oxygen species; $\mathrm{RPP}$, rate-pressure product; $\mathrm{SP}$, left ventricular systolic pressure; VPBs, ventricular premature beats

\section{INTRODUCTION}

Olanzapine belongs to the second generation of antipsychotics and is routinely used in the clinic for the treatment of schizophrenia. It is well known that schizophrenic patients suffer from cardiometabolic disorders (Jones et al., 2013; Pasternak et al., 2014; Wang et al., 2014), and administration of antipsychotic drugs is followed by higher morbidity and mortality (Jones et al., 2013). Several adverse effects, particularly prolonged QT intervals, higher rates of arrhythmias (Dineen et al., 2003; Drici et al., 1998; Gurovich et al., 2003), elevated risk of hyperlipidemia (Dudek et al., 2016; Horska et al., 2016; Takeuchi et al., 2015), increased blood glucose and lower circulating levels of free fatty acids (Albaugh et al., 2012; Klingerman et al., 2014) have been reported after olanzapine administration. Despite the fact that the incidence of sudden cardiac or sudden unexpected death in olanzapine-treated patients is twice as high as in nonusers (Salvo et al., 2016), the mechanism underlying the severe, adverse cardiac effects remains poorly understood.

Large amounts of energy must be generated in order to support the mechanical functions of the heart and disturbances in energy metabolism may be associated with cardiac dysfunction (Fillmore et al., 2014). Fatty acids and glucose are the two main sources of ATP in the heart. In addition to the substrate availability and end-product inhibition, two main signalling pathways regulate the cardiac energy metabolism: the Akt and 5'AMP-activated protein kinase (AMPK) signalling pathways. Under physiological conditions, Akt is activated by insulin or growth factors, and promotes glucose metabolism by stimulating translocation of the glucose transporters, primarily GLUT-4 in the heart, to the plasma membrane. Under conditions of metabolic stress, the AMPK pathway is activated and promotes production of energy via fatty acid oxidation and phosphorylation of the acetyl-CoA carboxylase (ACC) (Fillmore et al., 2014; Kang et al., 2012). Importantly, increased fatty acid oxidation in the heart inhibits glucose utilization and is associated with a decreased oxygen efficiency and reduced contractile function under certain conditions (Stanley et al., 1997). Furthermore, dysregulated fatty acid metabolism may lead to lipotoxicity, which refers to the accumulation of toxic lipid metabolic intermediates that may lead to cellular stress and dysfunction, and potentially cell death (D'Souza et al., 2016). 
Maintenance of energy homeostasis is crucial for preserving cellular physiology (Cieslak et al., 2016; Goralska et al., 2017). However, the involvement of the energy metabolism regulation in adverse cardiac effects of antipsychotics has not yet been investigated. Therefore, we investigated the effects of olanzapine on both, cardiac function and activation of key signalling molecules that regulate the energy metabolism in the isolated heart.

\section{METHODS}

Animals. Experiments were carried out according to Directive 2010/63/EU and were approved by Local Bioethical Committees.

Experimental design and isolated heart perfusions. Hearts were randomly divided into either olanzapine- or vehicle- treated hearts. Isolated heart preparations were established as described below. Isolated hearts, after a short stabilization period ( $15 \mathrm{~min})$, were perfused in the unloaded (Langendorff) mode for five minutes, to collect baseline measurements, and then continuously perfused with either the vehicle (aqua pro injectione) or $100 \mathrm{nmol} / 1$ olanzapine ( $\mathrm{Zy}$ prexa, Eli Lilly; Utrecht, NLD) via the aortic cannula for an additional 10 minutes (Fig. 1, upper panel). Two series of perfusions were performed: in the first $(n=5)$, the contractile function, coronary flow and ECGs were monitored; in the second $(n=3-4)$, the ventricular tissue was snap-frozen in liquid nitrogen at the end of the perfusion period and stored at $-80^{\circ} \mathrm{C}$ for biochemical analyses.

Male, Wistar rats (230-270 g, 4-5 months) were maintained on a standard laboratory chow and tap water ad libitum. Rats were anesthetized by i.p. injection of $100 \mathrm{mg} / \mathrm{kg}$ ketamine and $10 \mathrm{mg} / \mathrm{kg}$ xylazine, and, in the first series, anticoagulated with heparin (500 IU i.p.). Hearts were explanted and perfused via the aorta at $80 \mathrm{~mm} \mathrm{Hg}$ with a modified Krebs-Henseleit solution (Farine et al., 2016; Knezl et al., 2017) and gassed with $95 \% \mathrm{O}_{2}$ and $5 \% \mathrm{CO}_{2}$.

Functional measurements. For contractile measurements, a latex balloon was inserted into the left ventricle and pressure measurements were recorded using a LabChart 7 Pro version 7.3.7 (AD Instruments; Spechbach, Germany). Coronary effluent was harvested manually to determine the coronary flow 10 minutes after vehicle or olanzapine administration. For electrocardiogram (ECG) recordings, needle electrodes (AD Instruments; Spechbach, Germany) were inserted into the left ventricle. Electrode signals were
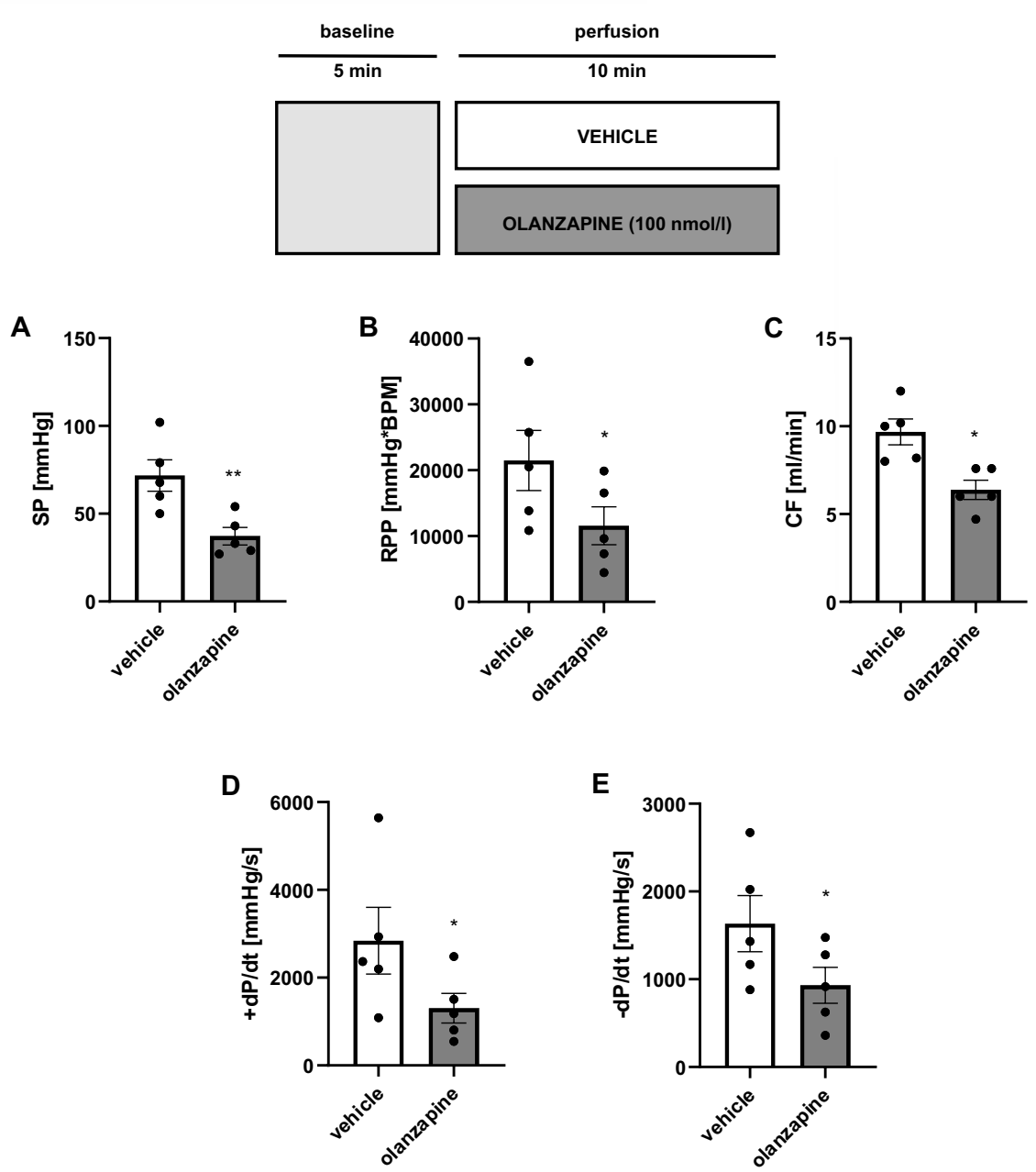

Figure 1. Experimental protocol and heart function.

Upper panel: Experimental protocol. Lower panels: Changes in hemodynamics after 10 min of either the vehicle $(n=5$, white box) or 100 $\mathrm{nmol} / /$ olanzapine $\left(\mathrm{n}=5\right.$, grey box) administration. (A) Left ventricular systolic pressure (SP; mmHg), ${ }^{* *} p<0.01$. (B) Rate pressure product (RPP; $\left.\mathrm{mmHg}^{*} \mathrm{BPM}\right),{ }^{*} p<0.05$. (C) Coronary flow $(\mathrm{CF} ; \mathrm{ml} / \mathrm{min}),{ }^{* *} p<0.01$. (D) Maximal rates of contraction $(+\mathrm{dP} / \mathrm{dt} ; \mathrm{mmHg} / \mathrm{s}),{ }^{*} p<0.05$. (E) Maximal rates of relaxation $\left(-\mathrm{dP} / \mathrm{dt}_{\min } ; \mathrm{mmHg} / \mathrm{s}\right),{ }^{*} p<0.05$. 
amplified with the FE136 Animal Bio Amplifier (AD Instruments; Spechbach, Germany) and recorded with a PowerLab 8/30 (AD Instruments; Spechbach, Germany). ECGs were recorded for the entire perfusion period.

Heart rate was calculated from the ECG recordings. Peak systolic pressure and their product (rate-pressure product; $\mathrm{RPP}),+\mathrm{dP} / \mathrm{dt}$ and $-\mathrm{dP} / \mathrm{dt}$ were calculated from the ventricular pressure measurements.

To evaluate ECGs, QT intervals were analyzed using LabChart 7 Pro version 7.3.7 (AD Instruments; Spechbach, Germany). Corrected QT (QTc) was analyzed according to the following formula: QTc $=Q T /(R R / f) 1 / 2$, where $\mathrm{f}$ is the normalization factor according to the basal RR interval duration in rats and equals $150 \mathrm{~ms}$ (Kmecova \& Klimas, 2010). To examine the effect on QT interval, averages of 10 consecutive beats from the 10th minute after vehicle or olanzapine administration were compared. Development of ventricular arrhythmias was defined according to the Lambeth Convention (Curtis et al., 2013). The sum of ventricular premature beats (VPBs) during $10 \mathrm{~min}$ of vehicle or olanzapine infusion was compared.

Isolation of ventricular cardiomyocytes. Ventricular cardiomyocytes were isolated as previously described (Ségalen et al., 2008). Briefly, isolated hearts were perfused via the aortic cannula with calcium-free Joklik's medium for $10 \mathrm{~min}$. Next, the heart was perfused with $0.09 \%$ collagenase and $0.7 \%$ BSA in Joklik's medium for $15 \mathrm{~min}$. After the atria removal, ventricles were opened and incubated in an incubation buffer $(10 \mathrm{ml}$ perfusate, $8 \mathrm{ml}$ Joklik's medium, and $2 \mathrm{ml} \mathrm{10 \%} \mathrm{BSA)}$ for $10 \mathrm{~min}$ at $37^{\circ} \mathrm{C}$. The heart was subsequently dissected and the suspension of cells was incubated at $37^{\circ} \mathrm{C}$ for $5 \mathrm{~min}$, whereas the $\mathrm{Ca}^{2+}$ concentration was increased every minute in steps of $200 \mu \mathrm{mol} / 1$ to 1 $\mathrm{mmol} / \mathrm{l}$. Next, the cell suspension was filtered through $180 \mu \mathrm{m}$ filter mesh and centrifuged at $17 \times \mathrm{g}$ for $1 \mathrm{~min}$. Cells were allowed to adhere to the laminin-coated plates in the HEPES-modified medium 199 with 10\% fetal calf serum for $1 \mathrm{~h}$. Finally, cardiomyocytes were treated with either the vehicle (0.001\% DMSO) or 100 $\mathrm{nmol} / 1$ olanzapine (Sigma Aldrich, St. Louis, USA) for $10 \mathrm{~min}$.

Immunoblotting. Frozen ventricular tissue or ventricular cardiomyocytes were homogenized in a lysis buffer containing Tris- $\mathrm{HCl}(20 \mathrm{mmol} / \mathrm{l})$, phenylmethylsulfonyl fluoride (1 $\mathrm{mmol} / \mathrm{l}), \mathrm{NaCl}$ (137 $\mathrm{mmol} / \mathrm{l})$, EGTA (1 $\mathrm{mmol} / \mathrm{l})$, EDTA (10 $\mathrm{mmol} / \mathrm{l})$, $\mathrm{NaF}(20 \mathrm{mmol} / \mathrm{l})$, sodium pyrophosphate $(1 \mathrm{mmol} / \mathrm{l})$, sodium orthovanadate $(1 \mathrm{mmol} / \mathrm{l})$, glycerol $(10 \%)$, NP-40 (1\%), aprotinin (4 $\mu \mathrm{g} / \mathrm{ml})$, leupeptin (4 $\mu \mathrm{g}$ ) $\mathrm{ml})$, and pepstatin $(4 \mu \mathrm{g} / \mathrm{ml})$. Lysates were centrifuged $\left(12000 \mathrm{rpm}, 20 \mathrm{~min}, 4 \mathrm{C}^{\circ}\right)$ and supernatants were stored at $-80^{\circ} \mathrm{C}$ until use. Total protein concentration of the supernatant was determined with the BCA protein assay kit (Pierce Biotechnology; Waltham, USA) according to the manufacturer's instructions. Lysates (75 $\mu \mathrm{g}$ protein) were separated on $7.5 \%$ SDS-polyacrylamide gels (BioRad; Hercules, USA), and transferred to nitrocellulose membranes (Li-COR Biosciences; Lincoln, USA). The membranes were blocked for $1 \mathrm{~h}$ with the Odyssey Blocking Buffer (Li-COR Biosciences; Lincoln, USA) in PBS and then incubated overnight at $4^{\circ} \mathrm{C}$ with anti-Akt (\#9272, 1:1000), anti-AS160 (\#2670, 1:1000), antiGSK-3ß (\#sc-9166, 1:500), anti-ACC (\#3676, 1:1000), anti-IR $\beta$ (\#sc-711, 1:500), anti-phosphoSer473-Akt (\#9271, 1:1000), anti-phosphoThr642-AS160 (\#4288,
1:1000), anti-phosphoSer9-GSK3 (\#9323, 1:1000), anti-phosphoSer79-ACC (\#11818, 1:1000). Anti-GSK$3 \beta$ and anti-IR $\beta$ were purchased from Santa Cruz Biotechnology (Dallas, USA). All other antibodies were purchased from Cell Signaling Technology (Danvers, USA). The following day, membranes were incubated with anti-mouse (Li-COR Biosciences; Lincoln, USA) or anti-rabbit (Invitrogen; Carlsbad, USA) secondary antibodies (1:10000) for $1 \mathrm{~h}$ at room temperature. Bands were detected with the Odyssey NIR imaging system (Li-COR Biosciences; Lincoln, USA).

ATP levels. Tissue ATP levels were determined spectrophotometrically as previously described (Niederberger et al., 2017). Briefly, frozen ventricular tissue was powdered, resuspended in perchloric acid $(7 \%)$, homogenized in a Dounce homogenizer and neutralized with $\mathrm{KOH}-\mathrm{KHCO}_{3}(1 \mathrm{~mol} / \mathrm{l})$. 200 $\mathrm{\mu l}$ of sample was then added to $800 \mu \mathrm{l}$ of the assay buffer containing Tris$\mathrm{HCl}(60 \mathrm{mmol} / \mathrm{l}, \mathrm{pH} 7.5), \mathrm{MgSO}_{4}(40 \mathrm{mmol} / \mathrm{l})$, glucose (2 mmol/l), nicotinamide adenine dinucleotide phosphate $(524 \mu \mathrm{mol} / \mathrm{l})$ and glucose- 6 phosphate dehydrogenase $(2 \mathrm{U} / \mathrm{ml})$. The ATP assay was initiated by adding hexokinase $(2 \mathrm{U} / \mathrm{ml})$ and absorbance was measured at $340 \mathrm{~nm}$. ATP levels were calculated after linear extrapolation from standard curves prepared with known quantities of ATP.

Isolation and function of the heart mitochondria. Heart mitochondria were isolated as previously described (Misak et al., 2013). Briefly, the heart was disrupted with scissors and a Potter-Elvehjem homogenizer with 20 strokes. Homogenate was centrifuged at $950 \times \mathrm{g}$ for $5 \mathrm{~min}$ at $4^{\circ} \mathrm{C}$. The remaining supernatant was decanted to a separate tube and centrifuged at $8500 \times g$ for $10 \mathrm{~min}$ at $4^{\circ} \mathrm{C}$. The pellet was resuspended in an isolation buffer $(65 \mathrm{mmol} / 1$ sucrose, $225 \mathrm{mmol} / 1$ mannitol, $0.25 \mathrm{mmol} / 1$ EDTA, $10 \mathrm{mmol} / 1 \mathrm{HEPES}, \mathrm{pH}$ 7.4) and centrifuged at $8500 \times \mathrm{g}$ for $10 \mathrm{~min}$ at $4^{\circ} \mathrm{C}$. Finally, the pellet was resuspended in a $400 \mu$ l volume of isolation buffer. Total protein $(\mathrm{mg} / \mathrm{ml})$ was determined using the Modified Lowry Protein Assay Kit (Thermo Fisher, Waltham, USA). Mitochondrial preparations were used within $2 \mathrm{~h}$. Functional parameters of isolated mitochondria were estimated by the Mitocell MT-200A system (Strathkelvin Instruments, Scotland). Mitochondria were resuspended in a respiration buffer (120 $\mathrm{mmol} / \mathrm{l} \mathrm{KCl}, 0.5 \mathrm{mmol} / 1 \mathrm{EGTA}, 3 \mathrm{mmol} / 1 \mathrm{KH}_{2} \mathrm{PO}$, $2 \%$ dextran, $12.5 \mathrm{mmol} / 1 \mathrm{HEPES}, \mathrm{pH} 7.4)$ at $30^{\circ} \mathrm{C}$ in the presence of substrates $(10 \mathrm{mmol} / 1$ glutamate +5 mmol/l malate) and treated with either the vehicle (0.001\% DMSO) or $100 \mathrm{nmol} / 1$ olanzapine (Sigma Aldrich, St. Louis, USA) for $10 \mathrm{~min}$. Next, $125 \mu \mathrm{mol} / 1$ ADP was added in order to induce state 3 (phosphorylating respiration) and $100 \mathrm{nmol} / \mathrm{l}$ carbonyl cyanide 4-(trifluoromethoxy) phenylhydrazone (FCCP) was added to induce state $3 \mathrm{u}$ (maximum uncoupler-stimulated respiration). Respiration rate before and after addition of the vehicle, olanzapine, ADP or FCCP was calculated as the negative slope of oxygen concentration. The ATP/O ratio (the relationship between ATP production and oxygen consumption) was calculated as the ratio between ADP added and the amount of oxygen consumed during state 3 .

Data analysis and statistics. The results are presented as mean values \pm S.E.M. Differences between groups were evaluated with t-tests. A value of $p<0.05$ was considered as significant. Analyses were performed with the GraphPad Prism (GraphPad Software, Inc.; San Diego, USA). The Shapiro-Wilk test was used to test distribution normality in the groups. 


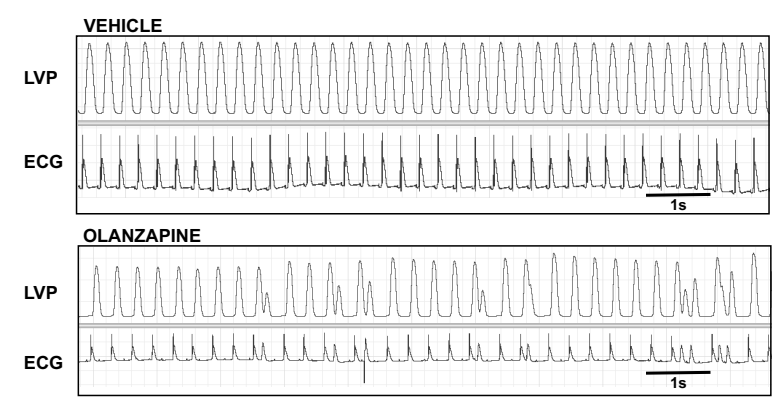

A

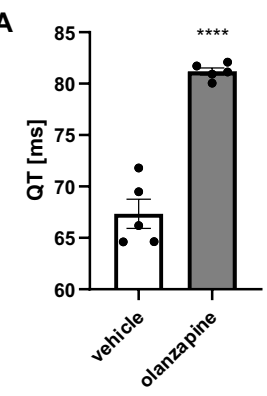

C

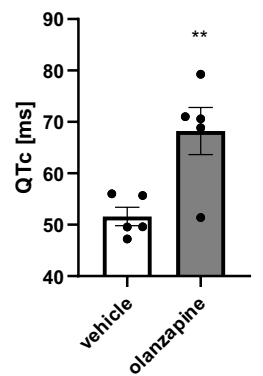

B

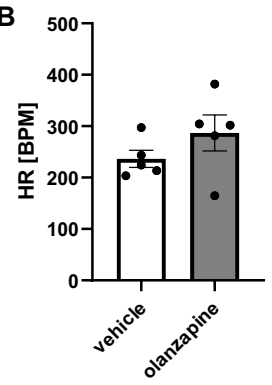

D

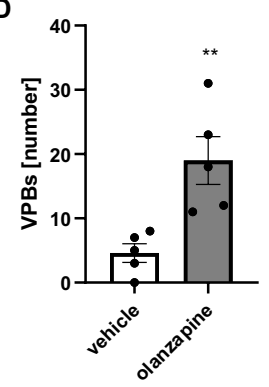

Figure 2. Changes in the electrical activity of the heart.

Changes in the electrical activity after 10 min of either the vehicle ( $n=5$, white box) or $100 \mathrm{nmol} / \mathrm{l}$ olanzapine $(n=5$, grey box) administration. Upper panels: Representative left ventricular pressure (LVP) and ECG recordings. Lower panels: (A) QT interval (QT), ${ }^{* * * *} p<0.0001$. (B) Heart rate (HR). (C) corrected QT interval (QTC), ${ }^{* *} p<0.01$. (D) Number of ventricular premature beats (VPBs), ${ }^{* *} p<0.01$.

\section{RESULTS}

\section{Effects of olanzapine on cardiac function}

We evaluated the effect of acute olanzapine treatment $(100 \mathrm{nmol} / 1,10 \mathrm{~min})$ on contractile function and electrical activity of isolated rat hearts. The contractile function in the olanzapine-treated hearts was depressed when compared to the vehicle-treated hearts, with significant reductions in the peak systolic pressure $(p=0.007$, Fig. 1A), rate pressure product $(p=0.02$, Fig. $1 \mathrm{~B})$, coronary flow $(p=0.01$, Fig. $1 \mathrm{C}),+\mathrm{dP} / \mathrm{dt}(p=0.03$, Fig. 1D) and $-\mathrm{dP} / \mathrm{dt}(p=0.03$, Fig. 1E). Next, we analysed the effect of olanzapine on electrical activity of the hearts. The olanzapine treatment resulted in a significant prolongation of the QT interval in comparison to the vehicle-treated isolated hearts $(p<0.0001$, Fig. 2A). There were no significant changes between the groups in the heart rate $(0.23$, Fig. $2 \mathrm{~B})$. The olanzapine administration significantly increased the QTc interval duration $(p=0.096$, Fig. 2C) and a higher incidence of ventricular arrhythmias was observed in olanzapine-treated hearts when compared to the vehicle-treated hearts $(p=0.007$, Fig. 2D).

\section{Effects of olanzapine on cardiac energy state and pathways regulating the energy metabolism}

To determine if olanzapine-mediated cardiotoxicity is associated with changes in regulation of the energy metabolism of the hearts, we examined the effect of acute olanzapine treatment $(100 \mathrm{nmol} / \mathrm{l}, 10 \mathrm{~min})$ on the cardiac ATP content. Significantly higher ATP levels were associated with the depressed cardiac function, in olanzapine-treated hearts ( $p=0.046$, Fig. 3A).

To investigate the mechanism by which olanzapine induces accumulation of ATP in the heart, we tested the influence of olanzapine on key regulators of fatty acid and glucose metabolism. ACC is a key regulator of fatty acid oxidation, and therefore we measured levels of total and phosphorylated $\left(\mathrm{Ser}^{79}\right)$ ACC in the isolated rat hearts. Acute administration of olanzapine $(100 \mathrm{nmol} / 1,10 \mathrm{~min})$ resulted in a significant increase in phosphorylation levels of ACC when compared to the vehicle-treated controls $(p=0.048$, Fig. 3B), indicating that olanzapine deactivates ACC and thus promotes oxidation of fatty acids with subsequent ATP generation.

In order to investigate the mechanism by which olanzapine affects the energy metabolism specifically in the 

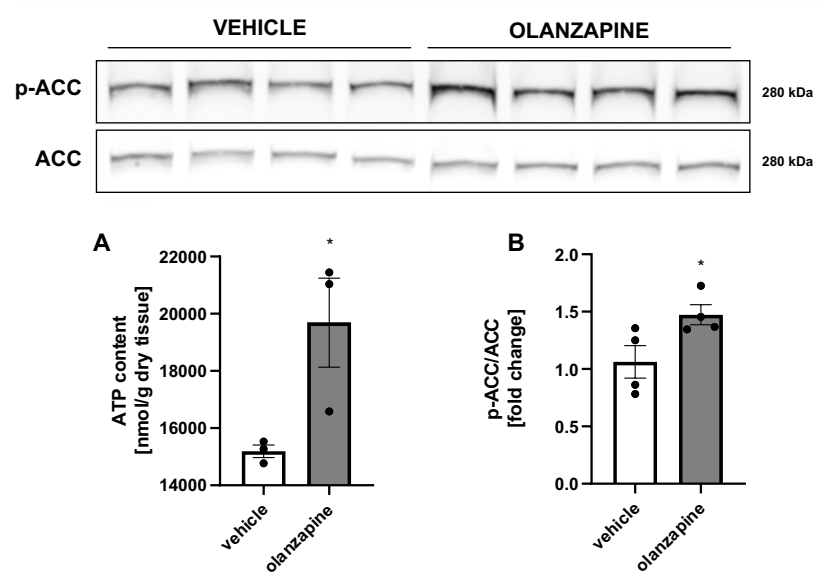

Figure 3. Influence of olanzapine perfusion on cardiac ATP content and phosphorylation of ACC protein in rat hearts.

Isolated rat hearts were perfused with either the vehicle $(n=3-4$, white bars) or $100 \mathrm{nmol} / \mathrm{l}$ olanzapine $(\mathrm{n}=3-4$, grey bars) for $10 \mathrm{~min}$. Upper panels: Representative western blots. Lower panels: densitometric quantification of (A) ATP content (nmol/g dry tissue), ${ }^{*} p<0.05$. (B) ACC phosphorylation levels (p-ACC/Akt vs. total ACC/Akt), ${ }^{*} p<0.05$.

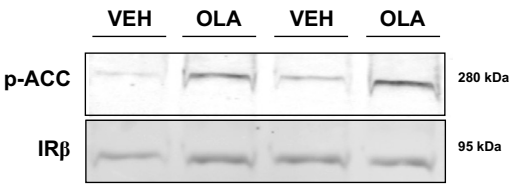

A

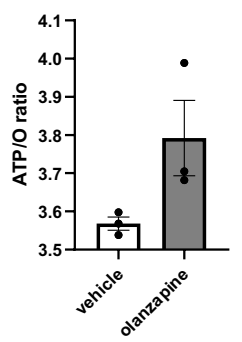

B

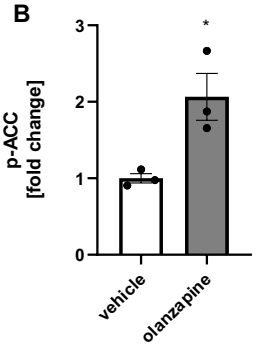

Figure 4. Influence of olanzapine on mitochondrial efficiency and phosphorylation of ACC protein in isolated cardiomyocytes. Isolated rat ventricular mitochondria and cardiomyocytes were incubated with either the vehicle ( $\mathrm{n}=3$, white bars) or $100 \mathrm{nmol} / \mathrm{l}$ olanzapine ( $n=3$, grey bars) for 10 min. Upper panels: Representative western blots. Lower panels: $(\mathbf{A})$ phosphorylation to oxidation rates (ATP/O) ratio. (B) Densitometric quantification of ACC phosphorylation levels ( $p-A C C / I R \beta$ or Akt), ${ }^{*} p<0.05$.

myocardium, we used isolated rat ventricular mitochondria and cardiomyocytes. We found a trend for higher $\mathrm{ATP} / \mathrm{O}$ ratio after olanzapine incubation as compared to the vehicle treated isolated mitochondria $(p=0.16$, Fig. 4A), however, these changes were not statistically significant. Olanzapine did not alter the rates of basal respiration and the rates of maximal respiration (data not shown). Similarly to the whole heart, incubation with olanzapine $(100 \mathrm{nmol} / 1,10 \mathrm{~min})$ significantly increased the level of phosphorylated ACC as compared to the vehicle treated isolated cardiomyocytes $(p=0.03$, Fig. 4B).

We also measured the effects of olanzapine on phosphorylation of key proteins in the glucose metabolism: Akt kinase $\left(\mathrm{Ser}^{473}\right)$, AS160 protein ( $\mathrm{Thr}^{642}$; regulator of GLUT4 trafficking), and GSK3 $\beta$ (Ser'; regulator of glycogen synthesis). Acute administration of olanzapine appeared to decrease phosphorylation of Akt $(\phi=0.07$, Fig. 5A) and its downstream targets AS160 ( $p=0.11$, Fig. 5B) and GSK3B ( $p=0.16$, Fig. 5C), however, these changes were not statistically significant.

\section{DISCUSSION}

Although olanzapine is one of the most prescribed antipsychotics for the treatment of schizophrenia, little is known about the molecular mechanisms of its adverse cardiac effects. We observed that acute olanzapine treatment was associated with a higher incidence of ventricular arrhythmias, as well as depressed contractile function and coronary flow in isolated rat hearts. In addition, we were able to demonstrate that olanzapine increases phosphorylation levels of ACC and tissue ATP levels in the heart, suggesting increased fatty acid oxidation. Furthermore, we observed a lower trend for phosphorylation of Akt, AS160 and GSK3B in olanzapine-treated hearts when compared to the vehicle-treated ones. These data indicate that acute exposure to olanzapine impairs cardiac rhythm and function in association with dysregulation of fatty acid metabolism in the isolated rat heart.

A higher incidence of sudden cardiac death has been linked to administration of antipsychotic drugs (Salvo et al., 2016), and QT prolongation and higher rates of arrhythmias have been reported in patients treated with 


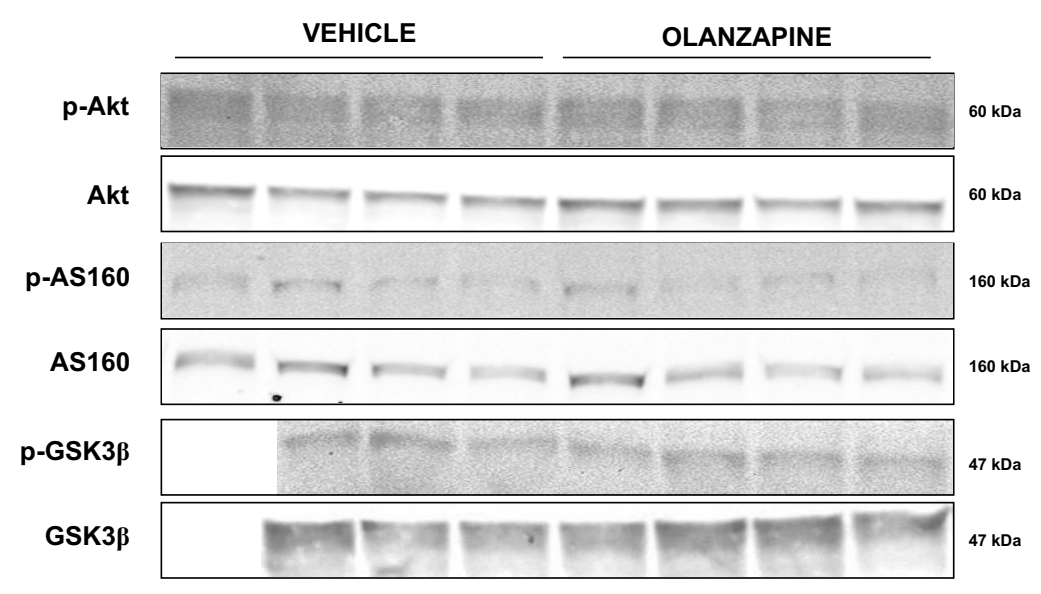

A

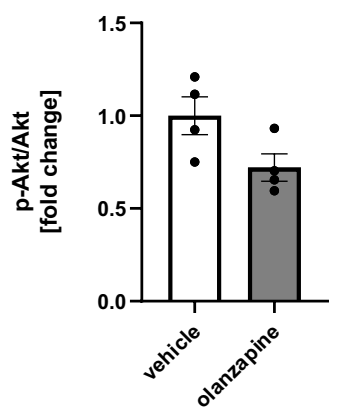

B

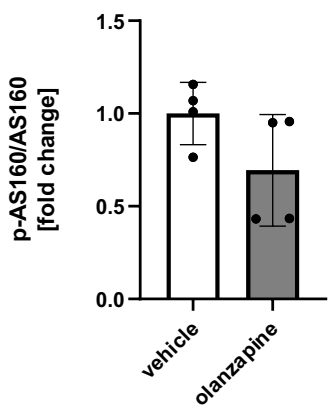

C

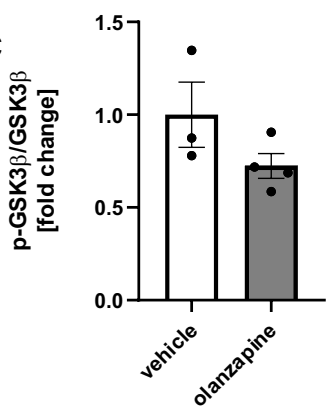

Figure 5. Influence of olanzapine perfusion on phosphorylation of Akt, AS160 and GSK3ß proteins in rat hearts.

Isolated rat hearts were perfused with either the vehicle ( $n=3-4$, white bars) or $100 \mathrm{nmol} / \mathrm{l}$ olanzapine $(\mathrm{n}=3-4$, grey bars) for $10 \mathrm{~min}$. Upper panels: Representative western blots. Lower panels: densitometric quantification of (A) Akt phosphorylation levels ( $p$-Akt/IR $\beta$ vs. total Akt/IR $\beta$ ). (B) AS160 phosphorylation levels (p-AS160/IR $\beta$ vs. total AS160/IR $\beta$ ). (C) GSK-3ß phosphorylation levels (p-GSK-3B/IR $\beta$ vs. total GSK-3ß/IR $\beta$ ).

olanzapine (Dineen et al., 2003; Drici et al., 1998; Guo et al., 2009; Gurovich et al., 2003). Consistent with previous studies, we observed a higher number of premature ventricular beats and an increase in the QTc interval after acute administration of $100 \mathrm{nmol} / 1$ olanzapine. The selected dose was based on steady-state plasma concentration of olanzapine, reaching $\sim 30 \mathrm{ng} / \mathrm{ml}(96 \mathrm{nmol} / \mathrm{l}$ ) with the use of $15 \mathrm{mg} /$ day (Attarbaschi et al., 2007; Fellows et al., 2003; Mauri et al., 2005; Weigmann et al., 2001). Blockage of hERG potassium channels results in increased action potential duration and represents one of the most common causes of QT prolongation (Recanatini et al., 2005). Furthermore, inhibition of hERG channels has been proposed as an underlying mechanism of olanzapine-induced impairment of the cardiac electrical activity (Lee et al., 2015), and response to treatment in schizophrenic patients is modulated by alterations in expression of the hERG isoforms in the brain (Apud et al., 2012). In addition, Morisette et al. reported that olanzapine blocks the rapid component of the delayed rectifier potassium current in guinea pig ventricular myocytes (Morissette et al., 2006). Thus, it is tempting to speculate that inhibition of specific potassium channels may be the mechanism by which olanzapine induces the prolonged QTc intervals following acute administration in isolated rat hearts.

Importantly, the observed disturbances in electrical activity of the heart after olanzapine administration were associated with depressed contractile function and reduced coronary flow. As the heart rate remained unchanged, decrease in the rate-pressure product resulted from a significant reduction in the peak systolic pressure. These findings are consistent with those of Leung and colleagues, who reported that a single olanzapine injection significantly decreased blood pressure and left ventricular contraction, but did not affect the heart rate in rats (Leung et al., 2014). In contrast, cumulative dose of olanzapine induced reduction in heart rate associated with a decrease in the developed pressure and coronary perfusion pressure in an isolated guinea pig heart (Guo et al., 2009). The decrease in coronary perfusion pressure could be responsible for the reduced coronary flow and contractility observed in our study. Under these conditions and according to our study in the isolated heart, we may conclude that olanzapine mediates changes in the cardiac functions via local, cardiac action(s), although the precise underlying mechanisms remain to be determined.

Under physiological conditions, the heart primarily uses fatty acids in order to meet its high energy demands. However, dysregulation of fatty acid metabolism may lead to accumulation of toxic lipid species, impaired myocardial contractility and arrhythmias (D'Souza et al., 2016; Schulze et al., 2016). ACC plays a crucial role in regulation of fatty acid oxidation. Under conditions of metabolic stress, ACC is phosphorylated and deactivated by 5'AMP-activated protein kinase (AMPK), thereby reducing production of the malonyl CoA and relieving its inhibition of carnitine palmitoyltransferase I (CPT-I), a key regulator of fatty acid cytosolic-mitochondrial trafficking. Excessive fatty acid oxidation may overwhelm capacity of the tricarboxylic acid cycle, thereby resulting 
in accumulation of toxic acylcarnitines (D'Souza et al., 2016). In the present study, olanzapine treatment was associated with a significantly higher phosphorylation of ACC and elevated ATP levels in the hearts, suggesting increased rates of mitochondrial fatty acid oxidation. The observed increase in phosphorylated ACC levels was also present in isolated rat ventricular cardiomyocytes, suggesting that olanzapine may alter the energy metabolism and thereby contractile function of cardiomyocytes. In contrast to our study, Takami et al. showed that apriprazol, but not olanzapine or other antipsychotics, increased phosphorylation of ACC, AMPK and intracellular ATP levels in PC12 cells (Takami et al., 2010). Reasons for these discrepant findings are unclear, but may result from the different models employed.

Several reports confirm that olanzapine mediated cytotoxicity is associated with increased production of reactive oxygen species (ROS) (Eftekhari et al., 2016; Heiser et al., 2010; Martins et al., 2008; Vucicevic et al., 2014). We observed a trend for higher mitochondrial efficiency in the presence of olanzapine. Since ROS are a direct by-product of ATP production in mitochondria (van Hameren et al., 2019), we may speculate that oxidative stress contributed to the electro-mechanical defects induced by olanzapine.

Increased fatty acid oxidation and/or lipotoxicity in the heart inhibit glucose uptake and metabolism (D'Souza et al., 2016; Schulze et al., 2016). Several studies suggest that glycolytically derived ATP is crucial for maintenance of the cellular ion homeostasis (Van Emous et al., 2001; Weiss \& Maslov, 2004; Xu et al., 1995). Since cytosolic malonyl-CoA levels reciprocally regulate fatty acid and pyruvate oxidation (Stanley et al., 1997), we may speculate that the lower activity of ACC may also be associated with lower activity of pyruvate dehydrogenase $(\mathrm{PDH})$ and a related electrical dysfunction (Rozanski \& Xu, 2002; Runnman et al., 1990; Stanley et al., 1997). In addition, accumulation of toxic lipid species has been linked with inhibition of Akt signalling, as well as disturbed AMPK activity (Schulze et al., 2016). In our study, acute administration of olanzapine appeared to lower phosphorylation of Akt and its downstream target AS160, a key regulator of GLUT4 trafficking. Similarly, phosphorylation of GSK3 $\beta$, regulating the glycogen synthesis, appeared to be decreased in olanzapine-treated hearts, which is in line with depressed Akt/GSK3 $\beta$ phosphorylation reported after olanzapine administration in the rat skeletal muscle and liver (Engl et al., 2005; Mondelli et al., 2013). Moreover, a recent report provided a direct link between AS160 phosphorylation levels and impaired electrical activity of the heart (Quan et al., 2015).

Cardiac energy requirements are extremely high in order to meet demands for contractile function, as well as maintenance of the ion gradients. It is important to note that cardiac ATP levels depend on both, the rates of production and utilization. Since we observed higher ATP levels in association with depressed cardiac function, we may speculate that lower utilization of ATP was responsible for this effect of olanzapine. Along different lines, both inhibition and augmentation of $K_{\mathrm{ATP}}$ channel activity have been reported after treatment with antipsychotics (Kinoshita et al., 2006; Yang et al., 2004). These channels are closed under physiological conditions and tend to open with metabolic stress in order to save energy. Previous studies demonstrated that blockage of $K_{\text {ATP }}$ channels was mediated by serotonin and histamine agonists (Bonev \& Nelson, 1996; Kleppisch \& Nelson, 1995; Yang et al., 2004). Given that olanzapine is a serotonin and histamine antagonist, it is possible that olanzapine promoted $K_{\mathrm{ATP}}$ channel opening. In addition, intracellular accumulation of fatty acids triggers the opening of $K_{\text {ATP }}$ channels (Liu et al., 2001), however $K_{\text {ATP }}$ activators fail to shorten the prolonged QT interval mediated by the hERG channel blockers (Testai et al., 2010). Based on these points, we may speculate that opening of the $K_{\text {ATP }}$ channels may contribute to the observed elevation of cardiac ATP content.

In conclusion, acute olanzapine administration led to impaired electrical activity, and reduced contractile function and coronary flow in the isolated rat heart. Our data support the concept that olanzapine stimulates fatty acid oxidation via phosphorylation and inactivation of ACC. Although the contractile function was reduced in olanzapine-treated hearts, cardiac ATP content was elevated. The antagonistic action of olanzapine on $\mathrm{H}_{1}$ receptors is one mechanism that may contribute to its metabolic and contractile effects in the heart. It should, however, be highlighted that further studies, particularly chronic and in vivo experiments, are needed to confirm this hypothesis.

\section{Acknowledgements}

The authors would like to thank Matej Vicen, Emilie Farine, Adrian Segiser and Anton Misak for technical and experimental support.

\section{Conflict of Interest}

None.

\section{REFERENCES}

Albaugh VL, Vary TC, Ilkayeva O, Wenner BR, Maresca KP, Joyal JL, Breazeale S, Elich TD, Lang CH, Lynch CJ (2012) Atypical antipsychotics rapidly and inappropriately switch peripheral fuel utilization to lipids, impairing metabolic flexibility in rodents. Schizophrenia Bulletin 38: 153-166. https://doi.org/10.1093/schbul/sbq053

Apud JA, Zhang F, Decot H, Bigos KL, Weinberger DR (2012) Genetic variation in $\mathrm{KCNH} 2$ associated with expression in the brain of a unique hERG isoform modulates treatment response in patients with schizophrenia. Am J Psychiatry 169: 725-734. https://doi. org/10.1176/appi.ajp.2012.11081214

Attarbaschi T, Sacher J, Geiss-Granadia T, Klein N, Mossaheb N, Lanzenberger R, Asenbaum S, Dudczak R, Kasper S, Tauscher J (2007) Striatal $\mathrm{D}(2)$ receptor occupancy in bipolar patients treated with olanzapine. Eur neuropsychopharmacol: J Eur College Neuropsychopharmacol 17: 102-107. https://doi.org/10.1016/j.euroneuro.2006.07.001

Bonev AD, Nelson MT (1996) Vasoconstrictors inhibit ATP-sensitive $\mathrm{K}^{+}$channels in arterial smooth muscle through protein kinase C. J General Physiol 108: 315-323. https://doi.org/10.1085/ jgp.108.4.315

Cieslak M, Czarnecka J, Roszek K (2016) The roles of purinergic signaling in psychiatric disorders. Acta Bochim Polon 63: 1-9. https://doi. org/10.18388/abp.2015_1004

Curtis MJ, Hancox JC, Farkas A, Wainwright CL, Stables CL, Saint DA, Clements-Jewery H, Lambiase PD, Billman GE, Janse MJ, Pugsley MK, Ng GA, Roden DM, Camm AJ, Walker MJ (2013) The lambeth conventions (II): Guidelines for the study of animal and human ventricular and supraventricular arrhythmias. Pharmacol Ther 139: 213-248. https://doi.org/10.1016/j.pharmthera.2013.04.008

D'Souza K, Nzirorera C, Kienesberger PC (2016) Lipid metabolism and signaling in cardiac lipotoxicity. Biochim Biophys Acta 1861: 15131524. https://doi.org/10.1016/j.bbalip.2016.02.016

Dineen S, Withrow K, Voronovitch L, Munshi F, Wally Nawbary M, Lippmann S (2003) QTc prolongation and high-dose olanzapine [3]. Psychosomatics 44: 174-175. https://doi.org/10.1176/appi. psy.44.2.174

Drici MD, Wang WX, Liu XK, Woosley RL, Flockhart DA (1998) Prolongation of QT interval in isolated feline hearts by antipsychotic drugs. J Clin Psychopharmacol 18: 477-481. https://doi. org/10.1097/00004714-199812000-00011

Dudek M, Kuder K, Kolaczkowski M, Olczyk A, Zmudzka E, Rak A, Bednarski M, Pytka K, Sapa J, Kieć-Kononowicz K (2016) H3 histamine receptor antagonist pitolisant reverses some subchronic 
disturbances induced by olanzapine in mice. Metabol Brain Dis 31: 1023-1029. https://doi.org/10.1007/s11011-016-9840-z

Eftekhari A, Azarmi Y, Parvizpur A, Eghbal MA (2016) Involvement of oxidative stress and mitochondrial/lysosomal cross-talk in olanzapine cytotoxicity in freshly isolated rat hepatocytes. Xenobiotica; Fate Foreign Comp Biol Sys 46: 369-378. https://doi.org/10.3109/004 98254.2015.1078522

Engl J, Laimer M, Niederwanger A, Kranebitter M, Starzinger M, Pedrini MT, Fleischhacker WW, Patsch JR, Ebenbichler CF (2005) Olanzapine impairs glycogen synthesis and insulin signaling in L6 skeletal muscle cells. Mol Psych 10: 1089-1096. https://doi. org/10.1038/sj.mp.4001729

Farine E, Niederberger P, Wyss RK, Méndez-Carmona N, Gahl B, Fiedler GM, Carrel TP, Tevaearai Stahel HT, Longnus SL (2016) Controlled reperfusion strategies improve cardiac hemodynamic recovery after warm global ischemia in an isolated, working rat heart model of donation after circulatory death (DCD). Front Physiol 7. https://doi.org/10.3389/fphys.2016.00543

Fellows L, Ahmad F, Castle DJ, Dusci LJ, Bulsara MK, Ilett KF (2003) Investigation of target plasma concentration-effect relationships for olanzapine in schizophrenia. Ther Drug Monitor 25: 682-689. https:// doi.org/10.1097/00007691-200312000-00006

Fillmore N, Mori J, Lopaschuk GD (2014) Mitochondrial fatty acid oxidation alterations in heart failure, ischaemic heart disease and diabetic cardiomyopathy. Brit J Pharmacol 171: 2080-2090. https:// doi.org/10.1111/bph.12475

Goralska J, Sliwa A, Gruca A, Razny U, Chojnacka M, Polus A, Solnica B, Malczewska-Malec M (2017) Glucagon-like peptide-1 receptor agonist stimulates mitochondrial bioenergetics in human adipocytes. Acta Biochim Pol 64: 423-429. https://doi.org/10.18388/ abp.2017_1634

Guo L, Dong Z, Guthrie H (2009) Validation of a guinea pig Langendorff heart model for assessing potential cardiovascular liability of drug candidates. J Pharmacol Toxicol Meth 60: 130-151. https://doi. org/10.1016/j.vascn.2009.07.002

Gurovich I, Vempaty A, Lippmann S (2003) QTc prolongation: Chlorpromazine and high-dosage olanzapine [1]. Can J Psych 48: 348. https://doi.org/10.1177/070674370304800513

Heiser P, Sommer O, Schmidt AJ, Clement HW, Hoinkes A, Hopt UT, Schulz E, Krieg JC, Dobschütz E (2010) Effects of antipsychotics and vitamin $\mathrm{C}$ on the formation of reactive oxygen species. J Psychopharmacol (Oxford, England). 24: 1499-1504. https://doi. org/10.1177/0269881109102538

Horska K, Ruda-Kucerova J, Babinska Z, Karpisek M, Demlova R, Opatrilova R, Suchy P, Kotolova H (2016) Olanzapine-depot administration induces time-dependent changes in adipose tissue endocrine function in rats. Psychoneuroendocrinol 73: 177-185. https:// doi.org/10.1016/j.psyneuen.2016.07.218

Jones ME, Campbell G, Patel D, Brunner E, Shatapathy CC, MurrayThomas T, van Staa TP3, Motsko S (2013) Risk of mortality (including sudden cardiac death) and major cardiovascular events in users of olanzapine and other antipsychotics: A study with the general practice research database. Cardiovasc Psych Neurol 2013. https:// doi.org/10.1155/2013/647476

Kang C, Lee H, Jung ES, Seyedian R, Jo M, Kim JS, Kim E (2012) Saffron (Crocus sativus L.) increases glucose uptake and insulin sensitivity in muscle cells via multipathway mechanisms. Food Chem 135: 2350-2358. https://doi.org/10.1016/j.foodchem.2012.06.092

Kinoshita H, Dojo M, Nakahata K, Kimoto Y, Kakutani T, Mizumoto K, Hatano Y (2006) Augmented activity of adenosine triphosphate-sensitive $\mathrm{K}^{+}$channels induced by droperidol in the rat aorta. Anesthesia Analgesia 102: 786-791. https://doi.org/10.1213/01. ane.0000195441.14929.6d

Kleppisch T, Nelson MT (1995) ATP-sensitive $\mathrm{K}^{+}$currents in cerebral arterial smooth muscle: pharmacological and hormonal modulation. Am J Physiol-Heart Circul Physiol 269: H1634-H1640. https://doi. org/10.1152/ajpheart.1995.269.5.H1634

Klingerman CM, Stipanovic ME, Bader M, Lynch CJ (2014) Secondgeneration antipsychotics cause a rapid switch to fat oxidation that is required for survival in C57BL/6J Mice. Schizophrenia Bull 40: 327-340. https://doi.org/10.1093/schbul/sbs196

Kmecova J, Klimas J (2010) Heart rate correction of the QT duration in rats. Eur J Pharmacol 641: 187-192. https://doi.org/10.1016/j. ejphar.2010.05.038

Knezl V, Sotníková R, Brnoliaková Z, Stankovičová T, Bauer V, Bezek Š (2017) Monotherapy of experimental metabolic syndrome: II. Study of cardiovascular effects. Inter Toxicol 10: 86-92. https://doi. org/10.1515/intox-2017-0014

Lee HJ, Choi JS, Hahn SJ (2015) Mechanism of inhibition by olanzapine of cloned hERG potassium channels. Neurosci Lett 609: 97-102. https://doi.org/10.1016/j.neulet.2015.10.039

Leung JY, Pang CC, Procyshyn RM, Barr AM (2014) Cardiovascular effects of acute treatment with the antipsychotic drug olanzapine in rats. Vasc Pharmacol 62: 143-149. https://doi.org/10.1016/j. vph.2014.06.003
Liu GX, Hanley PJ, Ray J, Daut J (2001) Long-chain acyl-coenzyme A esters and fatty acids directly link metabolism to K(ATP) channels in the heart. Circul Res 88: 918-924. https://doi.org/10.1161/ hh0901.089881

Martins MR, Petronilho FC, Gomes KM, Dal-Pizzol F, Streck EL, Quevedo J (2008) Antipsychotic-induced oxidative stress in rat brain. Neurotoxicity Res 13: 63-69. https://doi.org/10.1007/ BF03033368

Mauri MC, Steinhilber CP, Marino R, Invernizzi E, Fiorentini A, Cerveri G, Baldi ML, Barale F (2005) Clinical outcome and olanzapine plasma levels in acute schizophrenia. Eur Psychiatry 20: 55-60. https://doi.org/10.1016/j.eurpsy.2004.09.009

Misak A, Grman M, Malekova L, Novotova M, Markova J, Krizanova O, Ondrias K, Tomaskova Z (2013) Mitochondrial chloride channels: electrophysiological characterization and $\mathrm{pH}$ induction of channel pore dilation. Eur Biophys J 42: 709-720. https://doi. org/10.1007/s00249-013-0920-2

Mondelli V, Anacker C, Vernon AC, Cattaneo A, Natesan S, Modo M, Dazzan P, Kapur S, Pariante CM (2013) Haloperidol and olanzapine mediate metabolic abnormalities through different molecular pathways. Transl Psychiatry 3. https://doi.org/10.1038/tp.2012.138

Morissette P, Hreiche R, Mallet L, Vo D, Knaus EE, Turgeon J (2006) Olanzapine prolongs cardiac repolarization by blocking the rapid component of the delayed rectifier potassium current. J Psychopharmacol 21: 735-741. https://doi.org/10.1177/0269881106072669

Niederberger P, Farine E, Arnold M, Wyss RK, Sanz MN, MéndezCarmona N, Gahl B, Fiedler GM, Carrel TP, Tevaearai Stahel HT, Longnus SL (2017) High pre-ischemic fatty acid levels decrease cardiac recovery in an isolated rat heart model of donation after circulatory death. Metabolism 71: 107-117. https://doi.org/10.1016/j. metabol.2017.03.007

Pasternak B, Svanström H, Ranthe MF, Melbye M, Hviid A (2014) Atypical antipsychotics olanzapine, quetiapine, and risperidone and risk of acute major cardiovascular events in young and middle-aged adults: A nationwide register-based cohort study in Denmark. CNS Drugs 28: 963-973. https://doi.org/10.1007/s40263-014-0176-0

Quan C, Xie B, Wang HY, Chen S (2015) PKB-Mediated Thr649 Phosphorylation of AS160/TBC1D4 regulates the R-wave amplitude in the heart. PLOS ONE 10: e0124491. https://doi.org/10.1371/ journal.pone.0124491

Recanatini M, Poluzzi E, Masetti M, Cavalli A, De Ponti F (2005) QT prolongation through hERG $\mathrm{K}^{+}$channel blockade: Current knowledge and strategies for the early prediction during drug development. Med Res Rev 25: 133-166. https://doi.org/10.1002/med.20019

Rozanski GJ, Xu Z (2002) A metabolic mechanism for cardiac $\mathrm{K}^{+}$ channel remodelling. Clin Exp Pharmacol Physiol 29: 132-137. https://doi.org/10.1046/j.1440-1681.2002.03618.x

Runnman EM, Lamp ST, Weiss JN (1990) Enhanced utilization of exogenous glucose improves cardiac function in hypoxic rabbit ventricle without increasing total glycolytic flu. J Clin Invest 86: 12221233. https://doi.org/10.1172/JCI114828

Salvo F, Pariente A, Shakir S, Robinson P, Arnaud M, Thomas S, Raschi E, Fourrier-Réglat A, Moore N, Sturkenboom M, Hazell On Behalf Of Investigators Of The Aritmo Consortium L; Investigators of the ARITMO Consortium (2016) Sudden cardiac and sudden unexpected death related to antipsychotics: A meta-analysis of observational studies. Clin Pharmacol Ther 99: 306-314. https://doi. org/10.1002/cpt.250

Ségalen C, Longnus SL, Baetz D, Counillon L, Van Obberghen E (2008) 5-Aminoimidazole-4-carboxamide-1- $\beta$-D-ribofuranoside reduces glucose uptake via the inhibition of $\mathrm{Na}+/ \mathrm{H}+$ exchanger 1 in isolated rat ventricular cardiomyocytes. Endocrinol 149: 1490-1498. https://doi.org/10.1210/en.2007-1326

Schulze PC, Drosatos K, Goldberg IJ (2016) Lipid Use and Misuse by the Heart. Circul Res 118: 1736-1751. https://doi.org/10.1161/ CIRCRESAHA.116.306842

Stanley WC, Lopaschuk GD, Hall JL, McCormack JG (1997) Regulation of myocardial carbohydrate metabolism under normal and ischaemic conditions. Potential for pharmacological interventions. Cardiovascular Res 33: 243-257. https://doi.org/10.1016/s00086363(96)00245-3

Takami G, Ota M, Nakashima A, Kaneko YS, Mori K, Nagatsu T, Ota A (2010) Effects of atypical antipsychotics and haloperidol on PC12 cells: Only aripiprazole phosphorylates AMP-activated protein kinase. I Neural Transm (Vienna) 117: 1139-1153. https://doi. org/10.1007/s00702-010-0457-9

Takeuchi Y, Kajivama K, Ishiguro C, Uyama Y (2015) Atypical antipsychotics and the risk of hyperlipidemia: a sequence symmetry analysis. Drug Safety. 38: 641-650. https://doi.org/10.1007/s40264015-0298-4

Testai L, Cecchetti V, Sabatini S, Martelli A, Breschi MC, Calderone $\mathrm{V}$ (2010) Effects of $\mathrm{K}$ openers on the QT prolongation induced by HERG-blocking drugs in guinea-pigs. J Pharmacy Pharmacol 62: 924-930. https://doi.org/10.1211/jpp.62.06.0014

Van Emous JG, Vleggeert-Lankamp CL, Nederhoff MG, Ruigrok TJ, Van Echteld CJ (2001) Postischemic $\mathrm{Na}\left({ }^{+}\right)-\mathrm{K}\left({ }^{+}\right)$-ATPase reacti- 
vation is delayed in the absence of glycolytic ATP in isolated rat hearts. Am J Physiol Heart Circ Physiol 280: H2189-2195. https://doi. org/10.1152/ajpheart.2001.280.5.H2189

van Hameren G, Campbell G, Deck M, Berthelot J, Gautier B, Quintana P, Chrast R, Tricaud N (2019) In vivo real-time dynamics of ATP and ROS production in axonal mitochondria show decoupling in mouse models of peripheral neuropathies. Acta Neuropathol Commun 7: 86. https://doi.org/10.1186/s40478-019-0740-4

Vucicevic L, Misirkic-Marjanovic M, Paunovic V, Kravic-Stevovic T, Martinovic T, Ciric D, Maric N, Petricevic S, Harhaji-Trajkovic L, Bumbasirevic V, Trajkovic V (2014) Autophagy inhibition uncovers the neurotoxic action of the antipsychotic drug olanzapine. Autophagy 10: 2362-2378. https://doi.org/10.4161/15548627.2014.9842 70

Wang J, Liu YS, Zhu WX, Zhang FQ, Zhou ZH (2014) Olanzapineinduced weight gain plays a key role in the potential cardiovascular risk: Evidence from heart rate variability analysis. Sci Rep 4. https:// doi.org/10.1038/srep07394

Weigmann H, Gerek S, Zeisig A, Muller M, Hartter S, Hiemke C (2001) Fluvoxamine but not sertraline inhibits the metabolism of olanzapine: evidence from a therapeutic drug monitoring service. Therapeutic Drug Monitor 23: 410-413. https://doi.org/10.1097/00007691200108000-00015

Weiss RG, Maslov M (2004) Normal myocardial metabolism: Fueling cardiac contraction. Adv Studies Med 4: S457-S463

Xu KY, Zweier JL, Becker LC (1995) Functional coupling between glycolysis and sarcoplasmic reticulum $\mathrm{Ca}^{2+}$ transport. Circ Res 77: 88-97. https://doi.org/10.1161/01.res.77.1.88

Yang S-B, Proks P, Ashcroft FM, Rupnik M (2004) Inhibition of ATPsensitive potassium channels by haloperidol. Brit I Pharmacol 143: 960-967. https://doi.org/10.1038/sj.bjp.0706017 